\title{
Personality Traits, Risk Perception, and Protective Behaviors of Arab Residents of Qatar During the COVID-19 Pandemic
}

\author{
Mohamed Abdelrahman ${ }^{1}$ (iD \\ Published online: 22 June 2020 \\ C) Springer Science+Business Media, LLC, part of Springer Nature 2020
}

\begin{abstract}
During the 2020 COVID-19 pandemic, people in Qatar-similar to most countries globally - were instructed by health authorities to adopt protective behaviors to avoid infection. One of these behaviors is social distancing, which is influenced by diverse variables. Using data from an online survey with 405 responses, this study performed multiple regression analysis to explore effects of personality, risk perception, and personal hygiene practices on social distancing among residents of Qatar. The results showed that $87.3 \%$ of participants reported that they preferred to stay at home and not go outside unless necessary, $60.3 \%$ said that they maintain an adequate distance when communicating with others, $68.6 \%$ reported that they do not allow relatives and friends to visit them at home, $73.5 \%$ believed that COVID-19 is a dangerous disease, and $95.8 \%$ reported that they embrace personal hygiene practices and washing hands. Furthermore, multiple regression analysis showed that conscientiousness, neuroticism, risk perception, and personal hygiene practices predicted social distancing, with moderate effect sizes. Gender differences were also found in social distancing practices, indicating that women reported higher engagement in social distancing practices than men. These results highlighted the importance of individual differences in reacting to the COVID-19 pandemic and provide important information about the predictors of social distancing practices.
\end{abstract}

Keywords Personality $\cdot$ COVID-19 $\cdot$ Risk perception $\cdot$ Personal hygiene $\cdot$ Social distancing

Since the dawn of history, humans have experienced several waves of pandemic diseases that have caused hundreds of millions of deaths. Examples include influenza pandemics (Gagnon et al. 2015) and the HIV-AIDS pandemic (Merson 2006). At the time of this study in 2020, humanity is dealing with the COVID-19 pandemic (World Health Organization [WHO]

Mohamed Abdelrahman

mohamad.kamal@weyak.qa

1 Mental Health Friends Association, Duhail, P.O. Box 7409, Doha, Qatar 
2020a), which has to date killed around 150,000 people. The Middle East region has previously experienced one type of coronavirus in 2012, called Middle East respiratory syndrome (MERS) or MERS coronavirus (MERS-Cov). From 2012 to 2020, 23 cases were reported from Qatar as diseases transmitted from animals to humans (WHO 2020b). Nevertheless, MERS-Cov was not considered a pandemic because of the low rates of reported cases. A new member of this large family of coronaviruses is the novel coronavirus called COVID19, which has not previously been identified in humans.

During pandemics, people experience stressful circumstances that may affect their wellbeing - specifically, their psychological well-being. This has been confirmed by recent studies that demonstrate the psychological impact of COVID-19 on individuals' mental health. For example, Qiu et al. (2020) report that the recommended protective measures against COVID19 , such as self-isolation and home quarantine, have negative effects on individuals' mental health, inducing conditions such as panic disorder, anxiety, and depression. They add that incidence of these psychological disorders are high among migrant workers. Moreover, Zhang et al. (2020) show that patients who recovered from COVID-19, individuals under quarantine, and the general public developed depression and anxiety symptoms. Duan and Zhu (2020) report that people affected by the COVID-19 pandemic developed psychological distress and needed psychological intervention.

Considering the prevalence of mental health disorders in Qatar, depression was the most common mental disorder, followed by anxiety disorders (Ghuloum et al. 2011). Bener et al. (2015) found that $20 \%$ of Qataris who attend a primary health care center were diagnosed with at least one mental health disorder. They also found that the most common disorders were major depression (18.31\%), anxiety $(17.3 \%)$, and mood disorders $(16.95 \%)$. Using a representative sample of both migrants and non-migrants in Qatar, Khaled (2019) reports that the prevalence of major depression in individuals within the Arab ethnicity was $9.1 \%$ and $8.8 \%$ respectively. It was also found that Qatari nationals are less likely to be depressed than migrant workers (Khaled and Gray 2019).

The COVID-19 pandemic can be considered as an extremely stressful event; therefore, the Ministry of Public Health in collaboration with Primary Health Care Corporation and Hamad Medical Corporation in Qatar launched a telephone counseling helpline to provide support for those who developed mental health issues as a result of the pandemic (Ministry of Public Health 2020). In summary, the current study aims to determine how people respond within this very stressful context and the individual differences in how they react.

During a pandemic, most individuals uphold protective practices and take precautionary actions - such as social distancing — to avoid contagion (Brug et al. 2009; Ibuka et al. 2010). However, some individuals do not take such behavior seriously, endangering their own lives and those of others (Kamate et al. 2010; Van et al. 2010). In 2020, around 14,000 people from 13 countries on three continents participated in an international study carried out by the Institute of Global Health Innovation (2020) in the UK to explore the behavioral measures used by citizens of these countries to avoid COVID-19 infection. The study revealed that participants from Spain and Italy were most likely to stay home, while those from Sweden and Singapore were least likely. It also revealed that Italian participants had the highest rates of washing hands while Chinese had the lowest (Jones et al. 2020). Therefore, there is a need to explain why, during a pandemic, certain people engage in practices to avoid contagion while others do not?

Among the variables that predict the types of action people employ are personality traits. Existing studies have attested to the association between personality traits and various kinds of behaviors. For instance, Boone et al. (1999) demonstrated that personality has a substantial 
impact on cooperative behavior, such as following group rules and helping group members (Tyler and Blader 2001). Salgado (2002) showed that the Big Five personality traits predict deviant behavior, such as violating institutional rules.

Personality traits are also associated with health behavior. For example, individuals who score high on neuroticism are often worried about their health (Van Dijk et al. 2016) and therefore more likely to maintain good health habits such as oral hygiene (Meshram et al. 2017; Shanker et al. 2013). Mortensen et al. (2010) revealed that individuals who score low on agreeableness, extraversion, and openness to experience are more inclined to avoid infectious diseases. Bogg and Roberts (2004) reported that conscientiousness is linked to healthy behaviors, such as avoidance of risky sexual behavior and substance abuse.

In the context of a pandemic, people engage in behavioral practices to protect themselves from infection; these include social distancing and increased personal hygiene practices (Cowling et al. 2010; Reluga 2010). Social distancing refers to practices implemented by individuals to avoid contagion (Caley et al. 2008), such as reducing contact frequency with others (Reluga 2010), keeping adequate space between themselves and others when communicating face to face (Morrison and Yardley 2009), staying at home for extended periods, and avoiding crowds (Glass et al. 2006). Some studies found that voluntarily adopting social distancing is related to personality traits. For example, Jones and Salathé (2009) demonstrated that anxiety could predict engaging in protective behavior, such as avoiding crowded places.

Several studies also found gender differences in precautionary behaviors to avoid infection. For example, women are more likely to endorse social distancing and maintain personal hygiene practices than men (Liao et al. 2010; Park et al. 2010). Moran and Del Valle (2016) demonstrated that-compared with men-women are more likely to avoid crowds and physical contact with others to avoid respiratory pandemic diseases.

The implementation of protective health behavior such as social distancing is also related to risk perception (Caley et al. 2008; Pistone et al. 2007; Poletti et al. 2012), which is defined as one's assessment of hazardous objects or activities (Slovic et al. 1982). Leppin and Aro (2009) demonstrated that in the context of a respiratory pandemic disease, such as an influenza pandemic, risk perception is associated with protective behaviors such as frequent handwashing and avoidance of handshaking.

The climate in Qatar is dry and warm, where the temperature ranges from 35 to $45{ }^{\circ} \mathrm{C}$ in summer and from 15 to $30{ }^{\circ} \mathrm{C}$ in winter (Alsafran et al. 2017). Sorokowska et al. (2017) found that people living in warmer regions, when communicating with others, tend to keep less personal space compared to those living in cold places. Therefore, people in Qatar are expected not to apply social distancing in their daily conversations. Moreover, Feghali (1997) demonstrated that Arabs tend to keep closer personal distance during their communications to a degree that is considered unacceptable by westerners.

Furthermore, greeting among Arabs is considered very important to begin an interpersonal relationship or to establish a social conversation (Rababah and Malkawi 2012). It takes several forms such as handshakes, cheek to cheek kissing, or hugs (Al-Qaderi et al. 2017). Given that Arabs do not recognize - and may have never experienced - social distancing, we ask the following questions: in the context of a respiratory disease pandemic such as COVID-19, to what extent do Arabs practice social distancing? What are the predictors of social distancing to avoid COVID-19 infection in an Arab society? Are there gender differences in social distancing? This study therefore aimed to investigate the impact of personality traits, risk perception, and personal hygiene practices on social distancing to avoid COVID-19 infection among Arab residents of Qatar. 


\section{Method}

\section{Participants}

Data were collected online from 15 March to 24 April 2020 by a snowball sampling method and the target population was residents of Qatar. Sample size was calculated using the Cochran (1977) formula, with a predetermined margin of error of 5\% and confidence level of $95 \%$. The required sample size was 384 participants. Forty-six responses were added in case of dropouts. A total of 430 participants were recruited using convenience sampling. We excluded 25 cases because of incomplete responses. The final sample included 405 participants, of which $56.2 \%$ were women. Respondents were aged from 18 to 69 years $\left(M_{\mathrm{age}}=38.51, S D= \pm 10.53\right)$. Considering their level of education, $83 \%$ of respondents had a college degree and higher. Eligible participants had to be Arab residents in Qatar older than 18 years. Participation was voluntary and respondents were asked to complete an online questionnaire that was distributed to mobile phones of individuals connected to the author's social networks. The targeted subjects were also encouraged to distribute the questionnaire to their contacts who reside in Qatar. Approval for this study was obtained from the author's relevant institutional review board and respondents were asked to read a description of the study and provide written informed consent prior to completing the survey.

\section{Measures}

Big Five Personality Traits A 10-item short version of the Big Five Inventory (BFI-10) developed by Rammstedt and John (2007) was used. The questionnaire was translated from English to Arabic by the author and back-translated by a professional translator to ensure accuracy and internal consistency. This scale includes two items for each dimension and the items measured were openness to experience, conscientiousness, extraversion, agreeableness, and neuroticism. The questionnaire items include questions such as, "I see myself as someone who is: reserved, generally trusting." Participants were asked to report their level of agreement on a 5-point Likert scale ranging from $1=$ strongly disagree to $5=$ strongly agree. This short measure was used instead of a longer measure such as the 40-item IPIP because it has been previously shown to be reliable and there was a concern that participants in this population would be unwilling to complete a survey containing a longer scale.

Social Distancing This factor was assessed with three social distancing practices (Cronbach's $\alpha=.69$ ); the items were "I stay at home and don't go outside unless necessary," "I keep adequate distance when I communicate with others," and "I don't allow relatives and friends to visit me at home." Each item was rated on a 5-point Likert scale ranging from $1=$ never to $5=$ always. To calculate the percentage of participants who practiced each form of social distancing, response rates corresponding to scores of 4 or 5 were summed.

Personal Hygiene Practices A single item was used as a personal hygiene practice measure. The item was "I practice personal hygiene practices and handwashing." Participants rated their agreement or disagreement on a 5-point Likert scale. To calculate the percentage of participants who practiced good personal hygiene, response rates corresponding to "agree" and "strongly agree" were summed. 
Risk Perception A single item was used to assess to what extent an individual perceives COVID-19 as a dangerous disease. The item was "how do you rate the danger of COVID-19 disease?" Respondents assessed their responses on a scale ranging from $1=$ not dangerous at all to 5 = very dangerous. To calculate the percentage of participants who perceived COVID19 as dangerous, response rates corresponding to "very dangerous" and "dangerous" were summed.

\section{Statistical Analysis}

SPSS version 26 was used to analyze the collected data. Data transformation was performed for the social distancing, risk perception, and personal hygiene measures. Normality was tested for these variables using the Kolmogorov-Smirnov test. (This was not significant for social distancing and significant for risk perception and personal hygiene.) Pearson correlation coefficients were calculated to explore the relationships among the variables. Multiple linear regression analysis assumptions were examined. For the regression analysis, an analysis of standard residuals was carried out and showed that the data contained no outliers (Std. residuals $\min =-2.079$, Std. residuals $\max =3.123$ ). Multicollinearity was assessed using the variance inflation factor (VIF). We found that the assumption of multicollinearity was not problematic (openness, tolerance $=.98, \mathrm{VIF}=1.02$; conscientiousness, tolerance $=.75$, $\mathrm{VIF}=1.33$; extraversion, tolerance $=.99, \mathrm{VIF}=1.01$; agreeableness, tolerance $=.79, \mathrm{VIF}=$ 1.26; neuroticism, tolerance $=.83, \mathrm{VIF}=1.20$; risk perception, tolerance $=.96, \mathrm{VIF}=1.04$; personal hygiene, tolerance $=.92, \mathrm{VIF}=1.08)$. The data met the assumption of independent errors (Durbin-Watson value $=1.62$ ). The normal $P$ - $P$ plot of regression standardized residual of the dependent variable (social distancing) was checked and it looked normally distributed. Multiple regression analysis was performed to examine whether the independent variables predicted the dependent variable. The independent samples $t$ test was conducted to examine gender differences in social distancing at alpha $<.05$.

\section{Results}

Table 1 presents the percentages of social distancing practices, risk perception, and personal hygiene among the participants. The descriptive statistics show that $87.3 \%(31.5+55.8)$ of the participants reported that they prefer to stay at home and not go outside unless necessary, $60.3 \%(44.3+16)$ said that they maintain an adequate distance when communicating with others, $68.6 \%(34.2+34.4)$ reported that they do not allow relatives and friends to visit them at home, and $73.5 \%(25.1+48.4)$ believed that COVID-19 is a dangerous disease. Moreover, $95.8 \%(27.6+68.2)$ reported that they embrace personal hygiene practices and washing hands.

Table 2 shows the results of Pearson's correlation coefficient, which indicated a significantly positive correlation between social distancing and both conscientiousness $(r=.27$; $p<.001)$ and neuroticism $(r=.18 ; p<.001)$, while there was a significant negative correlation between social distancing and agreeableness $(r=-.11 ; p=.025)$. Additionally, risk perception $(r=.25 ; p<.001)$ and personal hygiene practices $(r=.48 ; p<.001)$ were both positively correlated with social distancing.

Table 3 illustrates the results of the multiple linear regression analysis, which indicated a collective significant effect between conscientiousness, neuroticism, risk perception, personal 
Table 1 Percentage distribution of social distancing, risk perception, and personal hygiene measures

\begin{tabular}{llr}
\hline Item & Response & $\%$ \\
\hline I maintain an adequate distance when communicating with others & Never & 3.3 \\
& Rare & 7.8 \\
& Sometimes & 28.7 \\
& Mostly & 44.3 \\
I do not allow relatives and friends to visit me at home & Always & 16 \\
& Never & 4.8 \\
& Rare & 7.8 \\
& Sometimes & 18.8 \\
I stay at home and do not go outside unless necessary & Mostly & 34.2 \\
& Always & 34.4 \\
& Never & 1.8 \\
& Rare & 2.8 \\
I embrace personal hygiene practices and washing hands & Sometimes & 8.3 \\
& Mostly & 31.5 \\
& Always & 55.8 \\
How do you rate the danger of COVID-19 disease? & Never & 1.8 \\
& Rare & 2.8 \\
& Sometimes & 8.3 \\
& Mostly & 31.5 \\
& Always & 55.8 \\
& Not dangerous at all & .3 \\
& Not dangerous & 2.9 \\
& Neutral & 23.3 \\
& Dangerous & 25.1 \\
& Very dangerous & 48.4 \\
\hline
\end{tabular}

hygiene practices, and social distancing practices. The model explained $29.2 \%$ of the variance $\left(F_{[7,391]}=23.01 ; p<.001 ; R^{2}=.292 ; d=.41\right)$. The individual predictors were examined further and these indicated that conscientiousness $(b=.112 ; S E=.011 ; p=.023)$, neuroticism $(b=.111 ; S E=.010 ; p=.018)$, risk perception $(b=.145 ; S E=.035 ; p=.001)$, and personal hygiene practices $(b=.451 ; S E=.044 ; p<.001)$ were significant predictors in the model.

Table 4 shows gender differences in social distance practices. These results indicate that women $(M=4.01 ; S D= \pm .818)$ were more likely to utilize social distancing $\left(t_{[398]}=-2.08\right.$; $p=.040 ; d=-.21)$ than men $(M=3.85, S D= \pm .75)$.

\section{Discussion}

Within the context of a pandemic such as COVID-19, individuals' reactions to the pandemic to avoid infection could be predicted by a variety of variables. This study aimed to ascertain the main determinants of social distancing adopted by Arab residents in Qatar to avoid infection with the pandemic disease COVID-19.

Referring particularly to the association between personality traits and social distancing, the results showed that agreeableness was negatively associated with social distancing, which indicates that individuals who are more sociable and prefer to participate in social eventssuch as volunteering activities and social interactions-were less likely to practice social distancing to avoid infectious disease. Since altruism, empathy, and helping behavior are the main characteristics of agreeable individuals (Graziano et al. 2007), they may prioritize social interactions and engage in social practices and feel less obligated to practice social distancing. 


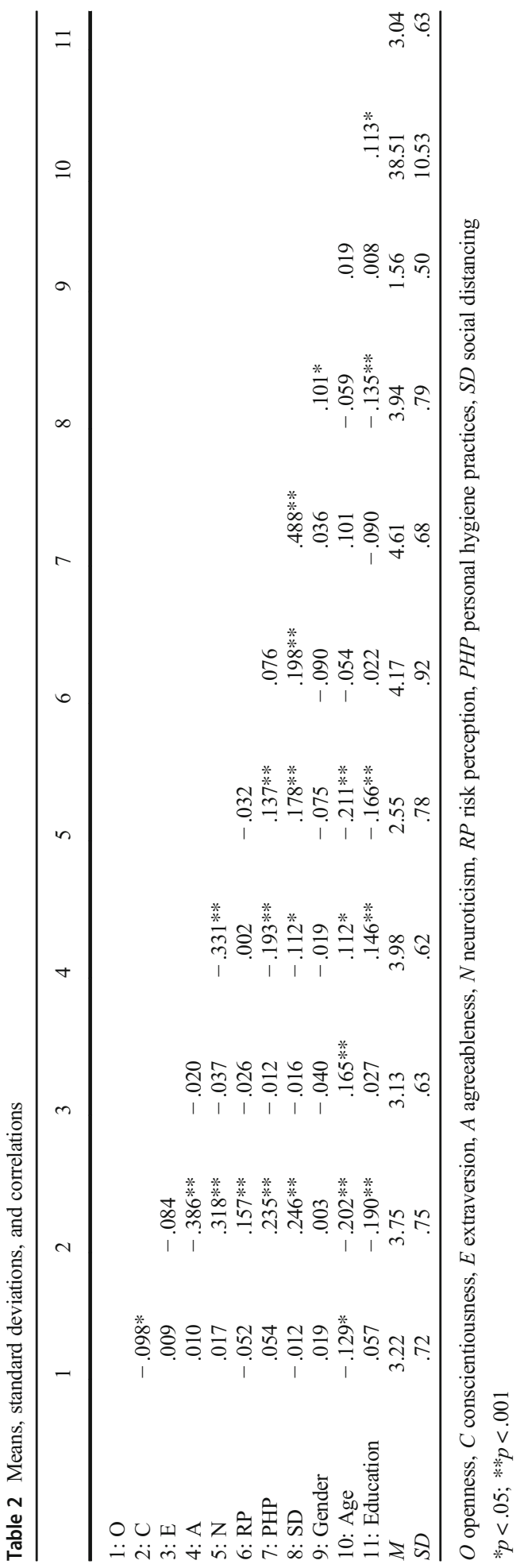


Table 3 The results of multiple regression analysis of social distancing practices on personality traits, risk perception, and personal hygiene practices

\begin{tabular}{|c|c|c|c|c|c|}
\hline \multicolumn{6}{|c|}{ Social distancing practices } \\
\hline Predictor & $B$ & $S E$ & $\beta$ & $t$ & $\operatorname{sig}$ \\
\hline Openness & .015 & .010 & .067 & 1.56 & .120 \\
\hline Conscientiousness & .024 & .011 & .112 & 2.29 & .023 \\
\hline Extraversion & .002 & .012 & .008 & .18 & .855 \\
\hline Agreeableness & .059 & .056 & .050 & 1.05 & .293 \\
\hline Neuroticism & .023 & .010 & .111 & 2.37 & .018 \\
\hline $\mathrm{RP}$ & .118 & .035 & .145 & 3.34 & .001 \\
\hline PH & .444 & .044 & .451 & 10.19 & .000 \\
\hline
\end{tabular}

$R P$ risk perception, $P H$ personal hygiene practices

This behavior may increase their likelihood of being infected with COVID-19. Furthermore, conscientiousness and neuroticism were shown to be positively associated with adopting social distancing to avoid COVID-19 infection. This means that individuals who are more inclined to comply with social norms and those who develop anxious and fearful feelings tend to practice social distancing.

In their study, Cowling et al. (2010) reported that high levels of anxiety were associated with lower rates of personal hygiene practices (handwashing) and higher levels of social distancing to avoid H1N1 contagion. Moreover, Trobst et al. (2002) found that individuals who score high on neuroticism tend to adopt risky sexual practices. The inconsistency in the behavior of people prone to neuroticism when dealing with a pandemic disease may be associated with their level of neuroticism. For example, individuals with high levels of fear and anxiety tend to adopt denial as a psychological defense mechanism to mitigate their fears; this means that they practice risky behaviors to feel psychologically secure (Aronson 2008; Florian and Mikulincer 1997; Peek et al. 2008).

In addition to the findings on personality traits, the results show that risk perception predicts social distancing. Hence, individuals who consider COVID-19 to be a serious danger are more inclined to adopt social distancing practices to avoid infection. These results corroborate those of previous studies (e.g., Brug et al. 2009; Ibuka et al. 2010; Walter et al. 2012). Furthermore, when an individual perceives a health risk factor, they react to the risk by attempting to find ways to avoid it. These solutions represent avoidance behavior that is adopted to survive an infectious disease. Our results also show that women are more likely to practice social distancing than men; these results coincide with those of prior studies (e.g., Liao et al. 2010; Moran and Del Valle 2016; Park et al. 2010).

The participants who declared that they maintain good personal hygiene practices were shown to be more likely to adopt social distancing. This variable is the most powerful predictor of social distancing practices. Since keeping personal hygiene practices helps to reduce the risk

Table 4 Gender differences in social distancing

Social distancing

\begin{tabular}{llllll}
\hline & $N$ & Mean & $S D$ & $t$ & $p^{*}$ \\
\hline Male & 176 & 3.85 & .82 & -2.06 & .040 \\
Female & 224 & 4.02 & .75 & & \\
\hline
\end{tabular}

$* p<.05$ 
of being infected (Aiello and Larson 2002), it could be inferred that an individual's personal perception of being clean motivates them to reinforce such behavior by adopting further actions, such as social distancing. Moreover, Qatar is considered to be a multinational society (Mahgoub and Qawasmeh 2012) so that members of each group may perceive other groups as outgroups; therefore, individuals who adhere to good personal hygiene practices might perceive others as "less clean" or more contaminated, which, in turn, increases the probability of being infected (Speltini and Passini 2014); thus, they embrace more protective behavior, such as social distancing.

The findings of this study provide a better understanding of individuals' responses to the pandemic based on personality traits and illustrate the importance of both risk perception and personal hygiene practices. During the pandemic, individuals' behavior could be predicted if we know information about their personality traits, so that health care providers can design appropriate interventions aimed at raising awareness among people in the community. Moreover, the present study assists in identifying the powerful role of personal hygiene practices that should be highlighted in national campaigns aimed at helping people in the community. Additionally, the association between risk perception and social distancing measures can be used to help reduce infection rates, which would help control the spread of the pandemic. Furthermore, based on the findings concerning gender differences in precautionary behaviors to avoid contagion (social distancing), our findings would be useful in encouraging media platforms to focus on presenting persuasive messages focused on men, as they are less likely to adopt protective behaviors.

Our study has limitations. First, the respondents were residents of Qatar of different Arab nationalities; therefore, their precautionary behavior (social distancing) may be affected by the culture of their home country. Second, the sample may not be representative of all nationalities in Qatar, particularly individuals of non-Arab nationalities working in Qatar, such as Indians, Filipinos, and Pakistanis; therefore, caution should be used when generalizing the results. Third, the scale developed for this study to assess social distancing practices during COVID19 in Qatar comprised three items that have acceptable reliability. However, it is necessary to develop and validate an extensive scale and re-examine the predictors of social distancing. Fourth, although self-reporting data can help in obtaining respondents' views and perspective, self-reported answers may be biased because of social desirability.

The current study sheds light on factors that could predict the adoption of precautionary behaviors (social distancing) to avoid infection during the COVID-19 pandemic. The main predictors are personality traits, risk perception, and personal hygiene practices. We suggest further research on the role of the neuroticism personality trait in predicting social distancing behavior, as there have been inconsistent findings concerning how individuals who are high in neuroticism behave in response to the pandemic. Further research is also recommended to investigate the impact of personal hygiene practices on social distancing from an interpersonal contact perspective.

Author Contributions Mohamed Abdelrahman was solely responsible for the entire work, including the study conception and design, material preparation, data collection and analysis, and writing the manuscript.

\section{Compliance with Ethical Standards}

Approval for this study was obtained from the author's relevant institutional review board and respondents were asked to read a description of the study and provide written informed consent prior to completing the survey.

Conflict of Interest The author declares that he has no conflicts of interest. 


\section{References}

Aiello, A. E., \& Larson, E. L. (2002). What is the evidence for a causal link between hygiene and infections? Lancet Infectious Diseases, 2(2), 103-110. https://doi.org/10.1016/s1473-3099(02)00184-6.

Al-Qaderi, I., Alduais, A., \& Wang, S. L. (2017). Non-verbal communication across cultures: a case study of Chinese, Polish, Turkish and (Yemeni) Arabic cultures. Научный результат. Вопросы теоретической и прикладной лингвистики [Research result]. Theoretical and Applied Linguistics, 3(3). https://doi. org/10.18413/2313-8912-2017-3-2-53.

Alsafran, M. H., Sarneel, J., \& Alatalo, J. M. (2017). Variation in plant litter decomposition rates across extreme dry environments in Qatar. The Arab World Geographer, 20(2), 252-260.

Aronson, E. (2008). Fear, denial, and sensible action in the face of disasters. Social Research, 75(3), 855-872.

Bener, A., Abou-Saleh, M. T., Dafeeah, E. E., \& Bhugra, D. (2015). The prevalence and burden of psychiatric disorders in primary health care visits in Qatar: too little time? Journal of family medicine and primary care, 4(1), 89-95.

Bogg, T., \& Roberts, B. W. (2004). Conscientiousness and health-related behaviors: a meta-analysis of the leading behavioral contributors to mortality. Psychological Bulletin, 130(6), 887-919. https://doi. org/10.1037/0033-2909.130.6.887.

Boone, C., De Brabander, B., \& Van Witteloostuijn, A. (1999). The impact of personality on behavior in five Prisoner's Dilemma games. Journal of Economic Psychology, 20(3), 343-377. https://doi.org/10.1016 /S0167-4870(99)00012-4.

Brug, J., Aro, A. R., \& Richardus, J. H. (2009). Risk perceptions and behaviour: towards pandemic control of emerging infectious diseases. International Journal of Behavioral Medicine, 16(1), 3-6. https://doi. org/10.1007/s12529-008-9000-x.

Caley, P., Philp, D. J., \& McCracken, K. W. J. (2008). Quantifying social distancing arising from pandemic influenza. Journal of the Royal Society Interface, 5(23), 631-639. https://doi.org/10.1098/rsif.2007.1197.

Cochran, W. G. (1977). Sampling techniques (3rd ed.). New York: John Wiley \& Sons.

Cowling, B. J., Ng, D. M., Ip, D. K., Liao, Q., Lam, W. W., Wu, J. T., Lau, J. T. F., Griffiths, S. M., \& Fielding, R. (2010). Community psychological and behavioral responses through the first wave of the 2009 influenza A (H1N1) pandemic in Hong Kong. Journal of Infectious Diseases, 202(6), 867-876. https://doi. org/10.1086/655811.

Duan, L., \& Zhu, G. (2020). Psychological interventions for people affected by the COVID-19 epidemic. The Lancet Psychiatry, 7(4), 300-302.

Feghali, E. (1997). Arab cultural communication patterns. International Journal of Intercultural Relations, 21(3), 345-378. https://doi.org/10.1016/S0147-1767(97)00005-9.

Florian, V., \& Mikulincer, M. (1997). Fear of death and the judgment of social transgressions: a multidimensional test of terror management theory. Journal of Personality and Social Psychology, 73(2), 369-380. https://doi.org/10.1037//0022-3514.73.2.369.

Gagnon, A., Acosta, J. E., Madrenas, J., \& Miller, M. S. (2015). Is antigenic sin always "original?" Reexamining the evidence regarding circulation of a human $\mathrm{H} 1$ influenza virus immediately prior to the 1918 Spanish flu. PLoS Pathogens, 11(3), e1004615. https://doi.org/10.1371/journal.ppat.1004615.

Ghuloum, S., Bener, A., \& Abou-Saleh, M. T. (2011). Prevalence of mental disorders in adult population attending primary health care setting in Qatari population. JPMA. Journal of the Pakistan Medical Association, 61(3), 216.

Glass, R. J., Glass, L. M., Beyeler, W. E., \& Min, H. J. (2006). Targeted social distancing designs for pandemic influenza. Emerging Infectious Diseases, 12(11), 1671-1681. https://doi.org/10.3201 /eid1211.060255.

Graziano, W. G., Habashi, M. M., Sheese, B. E., \& Tobin, R. M. (2007). Agreeableness, empathy, and helping: a person $\times$ situation perspective. Journal of Personality and Social Psychology, 93(4), 583-599. https://doi. org/10.1037/0022-3514.93.4.583.

Ibuka, Y., Chapman, G. B., Meyers, L. A., Li, M., \& Galvani, A. P. (2010). The dynamics of risk perceptions and precautionary behavior in response to 2009 (H1N1) pandemic influenza. BMC Infectious Diseases, 10(1), 296. https://doi.org/10.1186/1471-2334-10-296.

Institute of Global Health Innovation (2020) COVID-19 behavior tracker. How are behaviors changing in response to COVID-19. https://public.tableau.com/profile/ighi\#!/vizhome/ICLYouGovCovid-19Tracker_ V0_3/1Specificpreventativebehaviourbycountry. Accessed 20 May 2020.

Jones SP, Imperial College London Big Data Analytical Unit, \& YouGov Plc (2020) Imperial College London YouGov Covid Data Hub, v1.0. YouGov Plc.

Jones, J. H., \& Salathé, M. (2009). Early assessment of anxiety and behavioral response to novel swine-origin influenza A (H1N1). PLoS One, 4(12), e8032. https://doi.org/10.1371/journal.pone.0008032. 
Kamate, S. K., Agrawal, A., Chaudhary, H., Singh, K., Mishra, P., \& Asawa, K. (2010). Public knowledge, attitude and behavioural changes in an Indian population during the Influenza A (H1N1) outbreak. Journal of Infection in Developing Countries, 4(1), 7-14. https://doi.org/10.3855/jidc.501.

Khaled, S. M. (2019). Prevalence and potential determinants of subthreshold and major depression in the general population of Qatar. Journal of Affective Disorders, 252, 382-393.

Khaled, S. M., \& Gray, R. (2019). Depression in migrant workers and nationals of Qatar: an exploratory crosscultural study. International Journal of Social Psychiatry, 65(5), 354-367.

Leppin, A., \& Aro, A. R. (2009). Risk perceptions related to SARS and avian influenza: theoretical foundations of current empirical research. International Journal of Behavioral Medicine, 16(1), 7-29. https://oi. org/10.1007/s12529-008-9002-8.

Liao, Q., Cowling, B., Lam, W. T., Ng, M. W., \& Fielding, R. (2010). Situational awareness and health protective responses to pandemic influenza A (H1N1) in Hong Kong: a cross-sectional study. PLoS One, 5(10), e13350. https://doi.org/10.1371/journal.pone.0013350.

Mahgoub, Y., \& Qawasmeh, R. A. (2012). Cultural and economic influences on multicultural cities: the case of Doha, Qatar. Open House International, 37(2), 33-41.

Meshram, S., Gattani, D., Shewale, A., \& Bodele, S. (2017). Association of personality traits with oral health status: a cross-sectional study. International Journal of Indian Psychology, 4(2). https://doi.org/10.25215 /0402.167.

Merson, M. H. (2006). The HIV-AIDS pandemic at 25-the global response. New England Journal of Medicine, 354(23), 2414-2417. https://doi.org/10.1056/NEJMp068074.

Ministry of Public Health. (2020). Mental health and wellbeing. https://www.moph.gov. qa/english/Pages/Mental-Health-and-Wellbeing.aspx

Moran, K. R., \& Del Valle, S. Y. (2016). A meta-analysis of the association between gender and protective behaviors in response to respiratory epidemics and pandemics. PLoS One, 11(10), e0164541. https://oi. org/10.1371/journal.pone.0164541.

Morrison, L. G., \& Yardley, L. (2009). What infection control measures will people carry out to reduce transmission of pandemic influenza? A focus group study. BMC Public Health, 9(1), 258. https://doi. org/10.1186/1471-2458-9-258.

Mortensen, C. R., Becker, D. V., Ackerman, J. M., Neuberg, S. L., \& Kenrick, D. T. (2010). Infection breeds reticence: the effects of disease salience on self-perceptions of personality and behavioral avoidance tendencies. Psychological Science, 21(3), 440-447. https://doi.org/10.1177/0956797610361706.

Park, J. H., Cheong, H. K., Son, D. Y., Kim, S. U., \& Ha, C. M. (2010). Perceptions and behaviors related to hand hygiene for the prevention of H1N1 influenza transmission among Korean university students during the peak pandemic period. BMC Infectious Diseases, 10(1), 222. https://doi.org/10.1186/1471-2334-10-222.

Peek, M. E., Sayad, J. V., \& Markwardt, R. (2008). Fear, fatalism and breast cancer screening in low-income African-American women: the role of clinicians and the health care system. Journal of General Internal Medicine, 23(11), 1847-1853. https://doi.org/10.1007/s11606-008-0756-0.

Pistone, T., Guibert, P., Gay, F., Malvy, D., Ezzedine, K., Receveur, M. C., Siriwardana, M., Larouzé, B., \& Bouchaud, O. (2007). Malaria risk perception, knowledge and prophylaxis practices among travellers of African ethnicity living in Paris and visiting their country of origin in sub-Saharan Africa. Transactions of the Royal Society of Tropical Medicine and Hygiene, 101(10), 990-995. https://doi.org/10.1016/j. trstmh.2007.05.009.

Poletti, P., Ajelli, M., \& Merler, S. (2012). Risk perception and effectiveness of uncoordinated behavioral responses in an emerging epidemic. Mathematical Biosciences, 238(2), 80-89. https://doi.org/10.1016/j. mbs.2012.04.003.

Qiu, J., Shen, B., Zhao, M., Wang, Z., Xie, B., \& Xu, Y. (2020). A nationwide survey of psychological distress among Chinese people in the COVID-19 epidemic: implications and policy recommendations. General psychiatry, 33(2), e100213.

Rababah, M. A., \& Malkawi, N. A. A. (2012). The linguistic etiquette of greeting and leave-taking in Jordanian Arabic. European Scientific Journal, 8(18). https://doi.org/10.19044/esj.2012.v8n18p\%p.

Rammstedt, B., \& John, O. P. (2007). Measuring personality in one minute or less: a 10-item short version of the Big Five Inventory in English and German. Journal of Research in Personality, 41(1), 203-212. https://oi. org/10.1016/j.jrp.2006.02.001.

Reluga, T. C. (2010). Game theory of social distancing in response to an epidemic. PLoS Computational Biology, 6(5), e1000793. https://doi.org/10.1371/journal.pcbi.1000793.

Salgado, J. F. (2002). The Big Five personality dimensions and counterproductive behaviors. International Journal of Selection and Assessment, 10(1-2), 117-125. https://doi.org/10.1111/1468-2389.00198.

Shanker, R. K., Mohamed, M., Hegde, S., \& Kumar, M. S. A. (2013). Influence of personality traits on gingival health. Journal of Indian Society of Periodontology, 17(1), 58-62. https://doi.org/10.4103/0972-124 X.107476. 
Slovic, P., Fischhoff, B., \& Lichtenstein, S. (1982). Why study risk perception? Risk Analysis, 2(2), 83-93. https://doi.org/10.1111/j.1539-6924.1982.tb01369.x.

Sorokowska, A., Sorokowski, P., Hilpert, P., Cantarero, K., Frackowiak, T., Ahmadi, K. et al. (2017). Preferred interpersonal distances: a global comparison. Journal of Cross-Cultural Psychology, 48(4), 577-592. https://doi.org/10.1177/0022022117698039.

Speltini, G., \& Passini, S. (2014). Cleanliness/dirtiness, purity/impurity as social and psychological issues. Culture \& Psychology, 20(2), 203-219. https://doi.org/10.1177/1354067X14526895.

Trobst, K. K., Herbst, J. H., Masters, H., \& Costa, P. (2002). Personality pathways to unsafe sex: personality, condom use, and HIV risk behaviors. Journal of Research in Personality, 36(2), 117-133. https://oi. org/10.1006/jrpe.2001.2334.

Tyler, T. R., \& Blader, S. L. (2001). Identity and cooperative behavior in groups. Group Processes \& Intergroup Relations, 4(3), 207-226. https://doi.org/10.1177/1368430201004003003.

Van, D., McLaws, M. L., Crimmins, J., MacIntyre, C. R., \& Seale, H. (2010). University life and pandemic influenza: attitudes and intended behaviour of staff and students towards pandemic (H1N1) 2009. BMC Public Health, 10(1), 130. https://doi.org/10.1186/1471-2458-10-130.

Van Dijk, S. D. M., Hanssen, D., Naarding, P., Lucassen, P., Comijs, H., \& Oude Voshaar, R. (2016). Big Five personality traits and medically unexplained symptoms in later life. European Psychiatry, 38, 23-30. https://doi.org/10.1016/j.eurpsy.2016.05.002.

Walter, D., Böhmer, M. M., Reiter, S., Krause, G., \& Wichmann, O. (2012). Risk perception and informationseeking behaviour during the 2009/10 influenza A (H1N1) pdm09 pandemic in Germany. Eurosurveillance, 17(13), 20131.

World Health Organization. (2020a). Coronavirus disease 2019 (COVID-19): situation report, 51.

World Health Organization. (2020b). Middle East respiratory syndrome coronavirus (MERS-CoV)—Qatar. https://www.who.int/csr/don/12-march-2020-mers-qatar/en/

Zhang, J., Lu, H., Zeng, H., Zhang, S., Du, Q., Jiang, T., \& Du, B. (2020). The differential psychological distress of populations affected by the COVID-19 pandemic. Brain, behavior, and immunity, 87, 49-50. Advance online publication. https://doi.org/10.1016/j.bbi.2020.04.031

Publisher's Note Springer Nature remains neutral with regard to jurisdictional claims in published maps and institutional affiliations. 